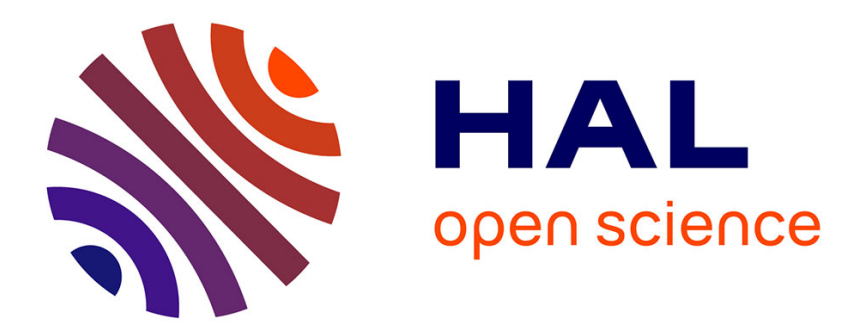

\title{
Internal Friction of Metastable Austenitic Stainless Steel SUS 301
}

\author{
I. Yoshida
}

\section{To cite this version:}

I. Yoshida. Internal Friction of Metastable Austenitic Stainless Steel SUS 301. Journal de Physique IV Proceedings, 1996, 06 (C8), pp.C8-385-C8-388. 10.1051/jp4:1996882 · jpa-00254690

\section{HAL Id: jpa-00254690 https://hal.science/jpa-00254690}

Submitted on 1 Jan 1996

HAL is a multi-disciplinary open access archive for the deposit and dissemination of scientific research documents, whether they are published or not. The documents may come from teaching and research institutions in France or abroad, or from public or private research centers.
L'archive ouverte pluridisciplinaire HAL, est destinée au dépôt et à la diffusion de documents scientifiques de niveau recherche, publiés ou non, émanant des établissements d'enseignement et de recherche français ou étrangers, des laboratoires publics ou privés. 


\title{
Internal Friction of Metastable Austenitic Stainless Steel SUS 301
}

\author{
I. Yoshida \\ Department of Materials Science, Iwaki Meisei University, Iwaki, Fukushima 970, Japan
}

\begin{abstract}
Anelastic measurements in the low frequency range have been made on a nickel reduced type metastable austenitic stainless steel SUS 301 . Cold working of various degrees was given by rolling after austenitizing heat treatment. Three internal friction peaks, $P_{1}, P_{2}, P_{3}$ from the lover temperatures, were observed. The sharp peak $P_{2}$ and the broad one $P_{3}$ disappeared by austenitization and reappeared by cold rolling. Peak $\mathrm{P}_{2}$ was a single relaxation type with an activation energy of about $0.5 \mathrm{eV}$. Electrical resistivity and thermopower were measured; it was revealed that the latter. was more sensitive to the martensitic transformation than the former.
\end{abstract}

\section{I NTRODUCT ION}

A stainless steel SUS 301 is known to harden remarkably by rolling at or above room temperature because of its rather high $M_{d}$ temperature, and it is widely used for purposes where a high strength is required. The content of the $T$ phase stabilizing element nickel is reduced compared with SUS 304, the so-called 18-8 stainless steel; therefore, a martensitic transformation takes place in this steel more easily than in SUS 304. Several works [1-4] have been reported on the internal friction of SUS 304, but no work on SUS 301, whose austenite is more unstable than SUS 304, and martensitic transformations occur progressively with lowering of temperature. It is of interest to know how mechanical properties, especially internal friction, change with temperature.

Purpose of the present work was to clarify how the internal friction of SUS 301 is influenced by the state of austenite phase and the amount of martensite which has already transformed. Another purpose was to investigate how the physical properties such as resistivity or thermopower are influenced by the phase transition. Since thermopower is sensitive to the electronic state it was expected to obtain more information by the measurement of thermopower than by resistivity.

\section{EXPERIMENTALS}

\section{1 Specimen preparation}

A commercial stainless steel sheet SUS 301 of thickness $1 \mathrm{~mm}$ was used. The chemical composition of the alloy is shown in the Table 1. Specimens were prepared by either rolling the starting material at room temperature or by rolling after austenitizing. In the table 2 are shown the reductions in rolling for each specimen. Specimen A was prepared by austenitizing the starting material at $1373 \mathrm{~K}$ for 1800 s. Specimens B, C and D were prepared by cold rolling specimen $A$, and $F$ and $G$ by cold rolling specimen $E$ which was the starting material. Specimens of the width $1 \mathrm{~mm}$ were slit from the sheet and served for. the internal friction and electrical measurements. 
2. 2 Method of measurement

2.2.1 Internal Friction

A low-frequency inverted torsion pendulum of Ke type (Sinku-Riko IFM 1500-L) was used. Measurements were made during thermal cycling between 100 and 300K. The cooling and heating rate was mostly $2 \mathrm{~K}$ min $^{-1}$, and the frequency was $0.9 \sim 1.5 \mathrm{~Hz}$. The calculation of the internal friction from the decay of oscillation and the recording of data were made automatically; the internal friction and the square of the frequency of oscillation versus temperature were plotted by a desk-top computer.

\subsubsection{Electrical Resistivity and Thermopower}

The electrical resistivity was measured on the same specimen as the internal friction by the dc four probe method. The thermopower was also measured on the same specimen. A temperature difference of few degrees was produced between two points along the specimen and the thermal electromotive force was measured.

\section{RESULTS AND DISCUSSION}

\section{1 Internal friction}

\subsubsection{Specimens $E$ and $A$}

Figure 1 shows the internal friction $Q^{-1}$ and the elastic modulus (the square of the frequency of torsional oscillation $f^{2}$ is used instead) of the specimen $E$, which is the as obtained starting material. The internal friction spectrum seems to consist of a sharp peak at $205 \mathrm{~K}$ and broader peaks which are not well defined. A modulus defect was observed corresponding to the $205 \mathrm{~K}$ sharp peak, but to broader peaks it is difficult to identify any distinctive modulus defect.

Figure 2 shows the result on the specimen $A$, which was fully austenitized. The sharp peak observed in the specimen E disappeared completely. A low broad peak was observed at lower temperatures (note that the ordinate scale is four times that of Figure 1).

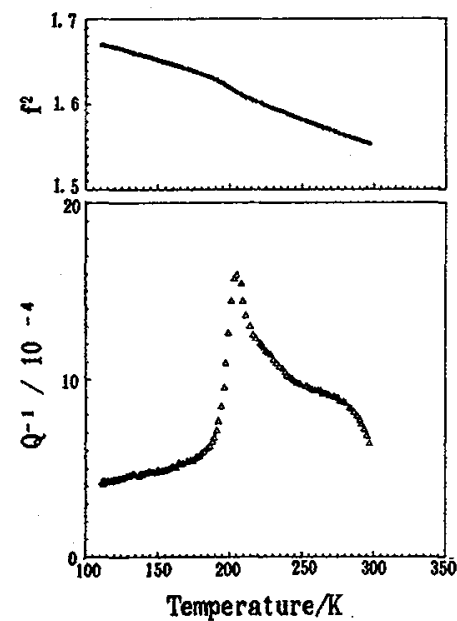

Figure 1: Internal friction and rigidity of specimen $E$.

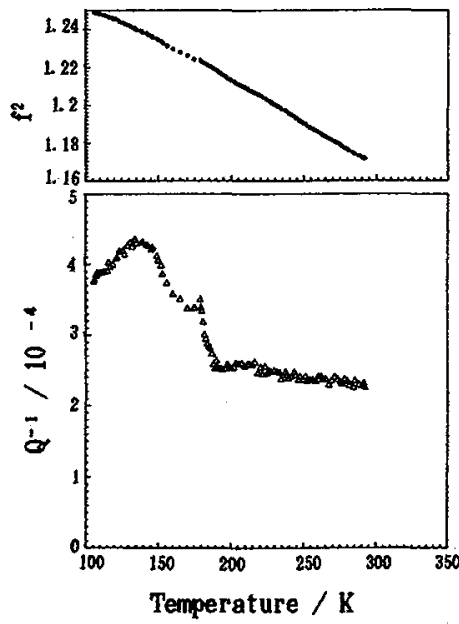

Figure 2: Internal friction and rigidity of specimen $A$.

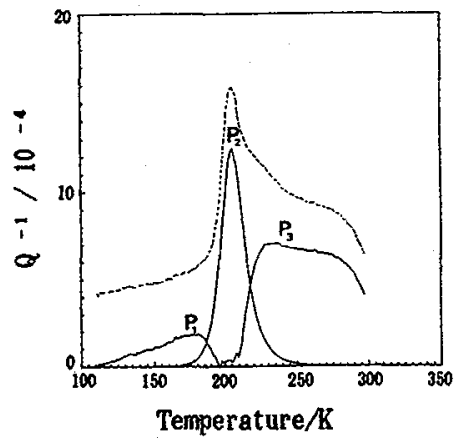

Figure 3: Decomposition of peak; specimen $E$. 
In order to investigate the nature of these internal friction peaks, we tried to decompose the spectrum assuming a back ground values. From figure 2 it is seen that the observed internal friction of specimen A at temperatures higher than 200K vary almost linearly and very slowly with temperature, and the values are fairly sma 11; therefore, we extrapolated them to lower temperatures and assumed them as the base line of internal friction data. Values of this base line were subtracted from the observed values of specimen $E$, and then a single relaxation curve was assumed for the sharp peak at 205K. Best fitting was made by adjusting three parameters, the peak temperature $T_{p}$, the height $H$ and half width $w$ of the peak. By subtracting the single relaxation curve from the observed curve, two broad peaks were identified as shown in the figure 3 . We call these peaks $P_{1}, P_{2}$ and $P_{3}$, respectively from the lowest temperature one.

For a single relaxation peak, the relaxation strength $\Delta$, activation energy $E$, and the pre-exponential factor of relaxation time $\tau_{0}$ are determined using $T_{p}, H$ and $w$ as follow.

$$
\begin{aligned}
& \Delta=2 H \\
& E=2.634 k T_{p}^{2} / w \\
& \tau_{0}=\exp \left(-E / k T_{p}\right) / \omega,
\end{aligned}
$$

where $k$ and $\omega$ are the Boltzmann constant and the angular frequency, respectively.

For $P_{2}$ peak of the specimen $E$, we obtained the following results;

$$
\Delta=25 \times 10^{-4}, \quad E=0.5 \mathrm{eV}, \quad \tau_{0}=6.4 \times 10^{-14}
$$

For peaks $P_{1}$ and $P_{3}$ it was impossible to decompose them any more; probably they consist of a group of small peaks which occur in succession.

A similar procedure of decomposition was applied to the specimen $A$. The result is shown in the figure 4. The $P_{3}$ peak has completely disappeared but the $P_{1}$ peak remained almost unchanged. A small sharp peak was observed at $179 \mathrm{~K}$, but it is not certain whether it is actually the same $P_{2}$ peak as in the specimen $E$, because its half width is very small ( $8 \mathrm{~K}$ ) and the assessed activation energy is $0.9 \mathrm{eV}$, nearly twice the size of that of the specimen $E$. A corresponding modulus defect was not observed also, therefore it shall be called $\mathrm{P}_{2}{ }^{\prime}$ peak for a while. This peak was observed only on cooling, and not on heating.

It is presumed that peaks $P_{2}$ and $P_{3}$ were produced by cold rolling and disappeared by annealing, while the peak $P_{2}{ }^{\prime}$ is different in nature.

\subsubsection{Specimens $B, C, F$ and $G$}

The specimen $A$ was given a strain by cold rolling to prepare specimens $B$ and $C$, the reductions being 6 or $8 \%$, respectively. On cold rolling peaks $P_{2}$ and $P_{3}$ reappeared. In the figure 5 we show the peak decomposition result on the specimen C. Three peaks $P_{1}, P_{2}$ and $P_{3}$, quite similar to the specimen $E$, were observed, but the height of peak $P_{2}$ was considerably lower than that of the specimen $E$.

Measurements were made on specimens which were given a further strain to the specimen $E ;$ i. $e,, F(10 \%)$ and $G(15 \%)$. Both results were similar to the specimen $E$, but $G$ was a little bit different. The figure 6 shows the peak decomposition result on the specimen $G$. It is remarkable that a small additional peak was observed at a lower temperature than $P_{2}$ of the specimen $E$. Its activation energy 
was calculated as $0.43 \mathrm{eV}$, a similar value to that of the specimen E. If we assume that this lower temperature peak was of relaxational origin, its activation energy would be $0.73 \mathrm{eV}$, rather similar to the peak $\mathrm{P}_{2}{ }^{*}$ of the specimen $A$. This peak was not observed on heating.

\subsubsection{Discussion}

Metastable austenitic stainiess steel undergoes a martensitic transformation, and internal friction peaks occur [5]. Peak $P_{3}$ occurred only in strained specimens presumably due to this mechanism. This explains why the specimen. A lacks $P_{3}$, because austenite phase in $A$ is more stabilized than in strained specimens. According to Pickering's equation [6], Ms temperature is estimated at 186K, while Tanino's equation [7] gives 148K. Although exact Ms temperature is difficult to determine, peak $P_{1}$ rough 1 y corresponds to $M s$, and $w i 11$ be interpreted in the same way as $P_{3}$, i.e, it occurs from progressing transformations. Peak $P_{2}$ is relaxational type accompanied with modulus defect, and is considered due to dislocations which have been created by preceding martensitic transformations. Peak $P_{z}^{\prime}$ is probably different from $P_{2}$ in its nature. We now presume that it is connected with some kind of martensitic transformation, and is not observed on heating because the inverse transformation does not occur at the same temperature.

\subsection{Electrical Resistivity and Thermopower}

The resistivity increased almost linearly with temperature, and any appreciable difference between specimens $E$ and $A$ was not observed, but in contrast the thermopower showed a remarkably different behaviour. As shown in the figure 7 , the absolute value of the thermopower of the specimen $A$ is smaller than that of the specimen $E$, which is qualitatively explained as the result of the difference between $A$ and $E$ in the temperature variation of the amount of martensite.

\section{CONCLUSION}

Several internal friction peaks were observed in metastable austenitic stainless steel SUS 301. Broad peaks $P_{3}$ and $P_{1}$ were interpreted as due to successively occurring martensitic transformations, while a sharp peak $P_{2}$, which was missing in the fully austenitized specimen, was considered a single relaxational peak with the activation energy of about $0.5 \mathrm{eV}$.

A remarkable difference was observed between thermopowers of austenitized and strained specimens. A possibility is pointed out that the thermopower can be a sensible method of detecting the amount of transformed phase.

\section{References}

[1]Baraz V.R., Grachev S.V. and Rolshchikov L.D., Steel USSR, (1972)672-672.

[2] Igata N., Chen H.B. and Miyahara K., Scripta Met., 16(1982)169.

[3]Igata N., Chen H.B. and Miyahara K., J. de Phys., 43(1982)C4-547.

[4] Igata N., Chen H.B. and Miyahara K. and Uba T., J. de Phys., 42(1982)C5-193.

[5]Yoshida I. and Otsuka H., J. Alloys and Compounds, 211/212(1994)208-211.

[6]Pickering F.B., Appl. Sci. Publ.London, (1978) 228.

[7]Tanino M. and Liu C.M., to be published. 